\title{
THE LONG-RUN RELATIONSHIP BETWEEN INFLATION AND REAL STOCK PRICES: EMPIRICAL EVIDENCE FROM SOUTH AFRICA*
}

\author{
Riona Arjoon ${ }^{1}$, Mariëtte Botes ${ }^{2}$, Laban K. Chesang ${ }^{3}$, Rangan Gupta ${ }^{4}$ \\ Department of Economics, University of Pretoria, Pretoria 0002, South Africa \\ E-mails: ${ }^{1}$ riona.arjoon@gmail.com; ${ }^{2}$ mariette.botes@gmail.com; \\ 3claban_2010@yahoo.com; ${ }^{4}$ rangan.gupta@up.ac.za (corresponding author) \\ Received 09 April 2011; accepted 29 June 2011
}

\begin{abstract}
The existing literature on the theoretical relationship between the rate of inflation and real stock prices in an economy has shown varied predictions about the long run effects of inflation on real stock prices. In this paper, we present some time series evidence on this issue using South African data, by applying the structural bivariate vector autoregressive (VAR) methodology proposed by King and Watson (1997). Our empirical results provide considerable support of the view that, in the long run real stock prices are invariant to permanent changes in the rate of inflation. The impulse responses reveal a positive real stock price response to a permanent inflation shock in the long run, indicating that any deviations in short run real stock prices will be corrected towards the long run value. It is therefore concluded that inflation does not lower the real value of stocks in South Africa, at least in the long run.
\end{abstract}

Keywords: inflation, real stock prices, vector autoregressive (VAR) model.

Reference to this paper should be made as follows: Arjoon, R.; Botes, M.; Chesang, L. K.; Gupta, R. 2012. The long-run relationship between inflation and real stock prices: empirical evidence from South Africa, Journal of Business Economics and Management 13(4): 600-613.

JEL Classification: C32, E31, G12.

\section{Introduction}

Traditional macroeconomic theory (assuming monetary super-neutrality) suggests that the real value of equity investments should not be affected by changes in the inflation rate. This stems from the reasoning that nominal variables should have no influence on the long-run values of real variables. This implies that, in times of inflation, investors sell financial assets in favour of equity, as stocks represent a claim on the real assets of a firm and this value should not be affected by changes in the price level. In other

\footnotetext{
* We would like to thank three anonymous referees, the associate editor and Professor Mehmet Balcilar for many helpful comments which markedly improved the quality of the paper. However, all remaining errors are solely ours.
} 
words, the return on assets should adjust to fully account for the inflation effect (Fisher $1930)^{1}$. Note, in addition to this, a Tobin (1965)-type effect could also result in a positive relationship between inflation and real stock prices, since higher inflation acts as a negative return on money, and savers substitute out of money into capital ${ }^{2}$.

A number of reasons have been offered to explain why an inverse relationship between inflation and stock prices is observed, contrary to the hypothesis put forward by Fisher (1930). The first is the inflation illusion hypothesis by Modigliani and Cohn (1979), which argues that participants in the stock market are unable to correctly calculate the long-term future growth rates of cash flows. At high inflation rates, the nominal interest rate is generally quite high, which causes an upward bias on the discount rate investors actually use for discounting. When expected returns are discounted using these higher rates, the result is a lower stock price level. The theory was developed in an attempt to explain the depressed stock prices in the US market in the 1960's and 1970's.

Evidence of inflation illusion has been documented by Ritter and Warr (2002), Campbell and Vuolteenaho (2004) and Hong and Lee (2011). Campbell and Vuolteenaho (2004) use a decomposition approach to estimate a residual mispricing component due to inflation based on US data. However, Rapach (2002), who used the King and Watson (1997) methodology of testing long run neutrality find little evidence of inflation illusion in stock market prices in a study of 16 industrialized countries. In a more recent study employing a dynamic general equilibrium with no inflation illusion involved, Wei (2010) finds that technology shock moves both inflation and stock returns in the same direction, resulting in a positive link between the two variables.

The second explanation is the real after-tax hypothesis offered by Feldstein (1980). The hypothesis argues that the tax treatment of depreciation costs and capital gains results in the decrease in stock prices during inflationary periods. Thus, corporate profits and inflation are inversely related because of higher effective tax rates arising from higher inflation. Marshall (1992) tests this hypothesis using inflation and asset returns in a monetary endowment economy and confirmed that it could be valid. The author observes that the inverse relationship will be less pronounced during periods when inflation is generated by monetary fluctuations. Quayes and Jamal (2008) also provide support for this hypothesis by showing that inflation results in a proportionate increase in the nominal value of stocks. However, due to the prevailing tax laws, stock prices will decline in real terms.

The third explanation is the proxy hypothesis due to Fama (1981) who attributes the negative relationship between inflation and stock prices to the change in expected economic growth that accompanies an increase in inflation rate. This hypothesis was tested and extended to include the effects of monetization of government deficits by Geske and Roll (1983). To formalize and derive testable implications of this hypothesis Gal-

\footnotetext{
${ }^{1}$ The Fisher (1930) hypothesis suggests a one-on-one relationship between inflation and stock prices, implying that in a competitive market, common stocks are a hedge against inflation.

${ }^{2}$ We would like to thank an anonymous referee for pointing this out to us.
} 
lagher and Taylor (2002) develop a theoretical model which decomposes inflation into a component due to supply shocks and a component due to demand shocks. They show stock prices to be significantly and negatively correlated with inflation via supply shocks (rather than demand shocks). Their findings support the proxy hypothesis since the component of inflation that is due to supply shocks act as a proxy for expected future movements in real activity in the economy.

Another possible link is the risk-premium hypothesis suggested by Devereux and Yetman (2002) and Anari and Kolari (2010). They maintain that nominal discount rates can have a negative impact on the value of stocks in the short run because of inflation premium that is included in the discounted rate. Closely related to this is the timevarying risk-aversion hypothesis, which argues that inflation changes the risk-averseness of investors and drives up the equity premium, and therefore the real discount rate (Brandt, Wang 2003).

Among the studies that focus on African stock market is the study by Alagidede and Panagiotidis $(2010)^{3}$, which employs parametric and nonparametric cointegration procedures to test for evidence of a positive long run relationship between stock prices and inflation. They show that the response of stock prices to a shock in consumer prices reveals an initial negative response in Egypt and South Africa, but then turns positive in the long run. For Nigeria, Kenya and Tunisia, the real stock price response to innovations in the consumer price index is invariant to the time horizon.

Although numerous studies have been conducted on the long run relationship between inflation and real stock prices, relatively little empirical evidence exists on long run superneutrality proposition in the South African stock market. The South African case is particularly interesting because over the past two decades the economy has experienced political and economic regime shifts which have influenced domestic policies. Of particular interest, is inflation targeting which was formally adopted as the monetary policy framework in the country since the year 2000. It would therefore be interesting to investigate the long run response of real stock prices under this economic environment.

In this paper, we apply the structural bivariate vector autoregressive (VAR) methodology proposed by King and Watson (1997), which pays particular attention to the integration and cointegration properties of the variables. Robustness checks suggested by King and Watson (1997) and also implemented by Rapach (2002) are applied in this paper by generating measures of the long run real stock price response to a permanent inflation shock for a range of assumed identifying parameter values.

Section 2 outlines the econometric framework, with particular focus on the time series properties of inflation and real stock prices, and the identification of the structural shocks. Empirical results are presented and discussed in Section 3. Section 4 concludes.

\footnotetext{
${ }^{3}$ The countries sampled for study by Alagidede and Panagiotidis (2010) are: Egypt, Kenya, Morocco, Nigeria, South Africa and Tunisia.
} 


\section{Data and econometric methodology}

\subsection{Data description}

The data used in this paper consists of quarterly observations of the nominal stock price index and consumer price index (CPI) for South Africa. It begins from 1980:1 and ends in 2010:2. The inflation rate series is computed by taking the first difference of the natural logarithm of the consumer price index, whereas the real stock price series is calculated as the natural logarithm of the nominal share price index deflated by the CPI.

\subsection{Integration and cointegration properties of the data}

Following King and Watson (1997) methodology, we evaluate a possible long run relationship between inflation and real stock prices using time series data for South Africa. In order to apply this methodology in estimating the long run response of real stock prices to a permanent inflation shock, it is critical to ascertain the time series properties of the two variables. Specifically, it is required that both inflation and real stock prices be integrated of order one (or I(1) in the terminology of Engel, Granger 1987) but not cointegrated $(\mathrm{CI}(1,1))$.

Essentially our interest is to determine whether permanent changes in the rate of inflation have any effect on the real stock price. This requires that both inflation rate and the real stock price are subject to permanent, or at least for practical purposes, very persistent shocks (Crosby, Otto 2000). If for instance, inflation is I(1) but real stock price is $\mathrm{I}(0)$ then permanent changes in the rate of inflation cannot (by definition) affect the real stock prices in the long run. In what follows, we perform unit root tests for inflation rate and real stock price series (based on two alternative testing procedures) and cointegration tests between the series.

Table 1 presents the results obtained from four standard unit root tests: the augmented Dickey-Fuller (ADF; Dickey, Fuller 1979), the Dickey-Fuller-GLS (Elliott et al. 1996), the NP (Ng, Perron 2001) and the KPSS (Kwiatkowski et al. 1992). The ADF, DF-GLS and NP test the null of unit root whereas the KPSS tests the null of stationarity. In these tests, we consider inflation and real stock prices in levels and in first differences where we include a constant and a linear trend. The ADF, DF-GLS and NP test results indicate that, whereas the null hypothesis of unit root cannot be rejected for inflation and real stock prices in levels, it is rejected in first differences. We note however that the ADF test shows inflation to be trend stationary in levels. Since this test is known to suffer potentially severe finite sample power and size problems, we rely on the results from DF-GLS, NP and KPSS tests.

For the KPSS test, stationarity serves as the null hypothesis. By testing both the unit root hypothesis and the stationarity hypothesis, one can distinguish series that appear to be stationary, series that appear to be integrated, and series that are not very informative about whether or not they are stationary or have a unit root (Koustas, Serletis 1999). The KPSS test results indicate that the null hypothesis of stationarity is rejected at $5 \%$ level for inflation and real stock prices in levels, but cannot be rejected for each variable in first differences. Combining the ADF, DF-GLS, NP and KPSS test results, we conclude that each variable (inflation and real stock prices) is integrated of order one (I(1)). 
Table 1. Unit root test results

\begin{tabular}{|c|c|c|c|c|}
\hline \multirow{2}{*}{ Test } & \multicolumn{2}{|c|}{ Inflation } & \multicolumn{2}{|c|}{ Real stock prices } \\
\hline & Levels & First difference & Levels & First difference \\
\hline $\mathrm{ADF}_{\mu}$ & -1.684 & $-7.194 * * *$ & -2.345 & $-7.848 * * *$ \\
\hline $\mathrm{ADF}_{\tau} \mathrm{DF}-\mathrm{GLS}_{\mu}$ & $-4.072 * * *$ & $-7.162 * * *$ & -3.190 & $-7.965^{* * *}$ \\
\hline DF-GLS & -0.832 & $-11.012 * * *$ & -1.298 & $-8.300 * * *$ \\
\hline $\mathrm{NP}_{\mu}-(\mathrm{MZa})$ & -2.642 & $-10.575 * * *$ & -1.426 & $-8.416^{* * *}$ \\
\hline$-(\mathrm{MZt})$ & -2.627 & $-109.41 * * *$ & -4.468 & $-55.73 * * *$ \\
\hline $\mathrm{NP}_{\tau}-(\mathrm{MZa})$ & -1.095 & $-7.301 * * *$ & -1.436 & $-5.278 * * *$ \\
\hline$-(\mathrm{MZt})$ & -13.113 & $-101.49 * * *$ & -5.782 & $-56.14 * * *$ \\
\hline $\mathrm{KPSS}_{\mu}$ & -2.526 & $-7.044 * * *$ & -1.653 & $-5.296 * * *$ \\
\hline \multirow[t]{2}{*}{$\mathrm{KPSS}_{\tau}{ }_{\tau}$} & $1.731 * * *$ & 0.030 & $0.940 * * *$ & 0.122 \\
\hline & $0.143^{*}$ & 0.026 & $0.369 * * *$ & 0.029 \\
\hline
\end{tabular}

Notes: ***,** and $*$ indicate the rejection of the null hypothesis of unit root at $1 \%, 5 \%$ and $10 \%$ level of Significance respectively, for the ADF, DF-GLS and NP tests.

$* * *, * *$ and $*$ indicate the rejection of the null hypothesis of stationarity at $1 \%, 5 \%$ and $10 \%$ level of significance respectively, for the KPSS test.

Critical values for the above tests at $1 \%, 5 \%$ and $10 \%$ level of significance are gives as follows:

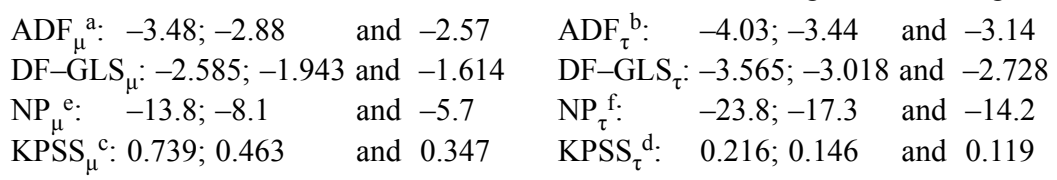

The King and Watson (1997) methodology relies on a bivariate vector autoregressive (VAR) model in first differences that is derived from a vector moving average process. The invertibility of this process requires that the endogenous variables in the VAR should not be integrated. In fact, long run neutrality tests are inefficient in the presence of cointegration (Fisher, Seater 1993). If for instance inflation and real stock price are nonstationary but are cointegrated, then a finite VAR process in first differences does not exist for the variables. To present an empirical evidence of this issue using our data, we first test for cointegration between inflation and real stock prices using the augmented Engel and Granger (1987, AEG) two-step procedure, whereby non-cointegration is the null hypothesis. We assume a constant in the cointegration regression, and use the Akaike Information Criterion (AIC) to determine the number of augmenting lags in the test. The results are reported in Table 2 where inflation and real stock prices serve in turn as the dependent variable in the first step OLS regression. In both cases, the test results suggest that the null hypothesis of non-cointegration is not rejected at the $5 \%$ level. Table 2 also reports cointegration test results between inflation and real stock prices based on the Shin (1994) two-step procedure, where cointegration serves as the null hypothesis. As in the AEG (1987) two-step procedure, we report $C_{\mu}$ statistics from Shin (1994) by assuming a constant in the cointegration regression, and we use inflation and real stock prices in turn as the dependent variable in the first step. The test results based on the $C_{\mu}$ statistics do confirm those inferred based on the AEG statistics, that inflation 
Table 2. Cointegration test results

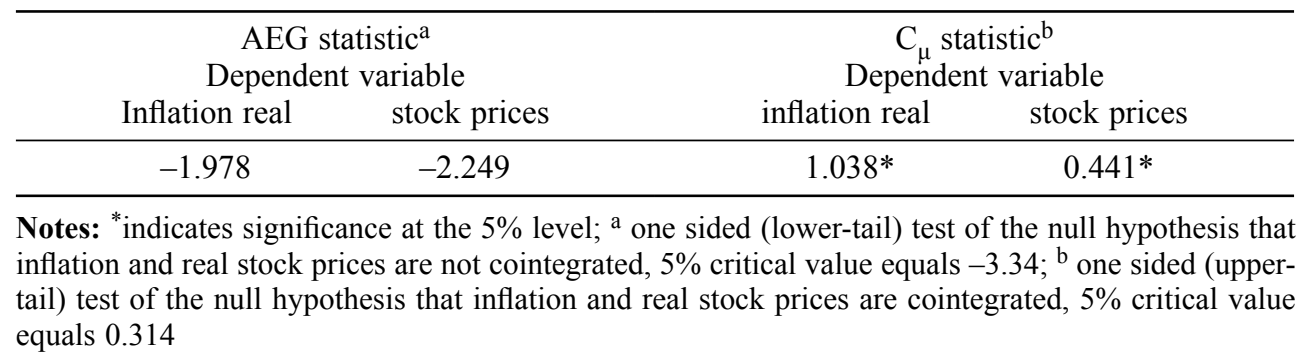

and real stock prices are indeed non-cointegrated. Overall, we can reasonably consider inflation and real stock prices as integrated of order one (I(1)) but not cointegrated for South Africa. This means that the conditions necessary for meaningful examination of the long run neutrality tests hold.

\subsection{Econometric framework}

We define $\pi_{t}$ and $s_{t}$ to be, respectively, inflation rate and natural logarithm of real stock prices at time $t$. Following the methodology developed by King and Watson (1997) and adopted by Rapach (2002), we specify the following bivariate vector autoregressive (VAR) model of order $p$ in $\pi_{t}$ and $s_{t}$ expressed in first difference form (in which case $\pi_{t}$ and $s_{t}$ are I(1) but not cointegrated).

$$
\begin{aligned}
\Delta \pi_{t} & =\lambda_{\pi s} \Delta s_{t}+\sum_{j=1}^{p} \alpha_{\pi s}^{j} \Delta s_{t-j}+\sum_{j=1}^{p} \alpha_{\pi \pi}^{j} \Delta \pi_{t-j}+\varepsilon_{t}^{\pi} . \\
\Delta s_{t} & =\lambda_{s \pi} \Delta \pi_{t}+\sum_{j=1}^{p} \alpha_{s s}^{j} \Delta s_{t-j}+\sum_{j=1}^{p} \alpha_{s \pi}^{j} \Delta \pi_{t-j}+\varepsilon_{t}^{s} .
\end{aligned}
$$

Equations (1) and (2) are a set of dynamic simultaneous equations in which: $\varepsilon_{t}^{\pi}$ and $\varepsilon_{t}^{s}$ represent exogenous unexpected changes in inflation and real stock prices respectively, that can have permanent effect on the levels of the endogenous variables $\pi_{t}$ and $s_{t}$; respectively, $\lambda_{\pi s}$ and $\lambda_{s \pi}$ represent contemporaneous response of $\pi_{t}$ to changes in $s_{t}$ and the contemporaneous response of $s_{t}$ to changes in $\pi_{t}$ respectively. Our main focus is on the dynamic effect of the inflation shock, $\varepsilon_{t}^{\pi}$ on $s_{t}$.

Representing the above system in matrix format yields;

$$
\alpha(L) X_{t}=\varepsilon_{t}
$$

in which,

$$
\begin{array}{lll}
\alpha(L)=\sum_{j=0}^{p} \alpha_{j} L^{j}, & X_{t}=\left[\begin{array}{c}
\Delta \pi_{t} \\
\Delta s_{t}
\end{array}\right], & \varepsilon_{t}=\left[\begin{array}{c}
\varepsilon_{t}^{\pi} \\
\varepsilon_{t}^{s}
\end{array}\right], \\
\alpha_{0}=\left[\begin{array}{cc}
1 & -\lambda_{\pi s} \\
-\lambda_{s \pi} & 1
\end{array}\right], & \alpha_{j}=-\left[\begin{array}{cc}
\alpha_{\pi \pi}^{j} & \alpha_{\pi s}^{j} \\
\alpha_{s \pi}^{j} & \alpha_{s s}^{j}
\end{array}\right], & j=1,2, \ldots, p,
\end{array}
$$

where we define

$$
\alpha_{\pi \pi}=1-\sum_{j=1}^{p} \alpha_{\pi \pi}^{j} \alpha_{j} L^{j} ; \quad \alpha_{\pi s}(L)=\lambda_{\pi s}+\sum_{j=1}^{p} \alpha_{\pi s}^{j} L^{j} ; \quad \alpha_{s s}=1-\sum_{j=1}^{p} \alpha_{s s}^{j} L^{j}
$$


and $\quad \alpha_{s \pi}=\lambda_{s \pi}+\sum_{j=1}^{p} \alpha_{s \pi}^{j} L^{j}$.

By letting $\varepsilon_{t}=\left(\varepsilon_{t}^{\pi} \varepsilon_{t}^{s}\right)^{\prime}$ we define $E\left(\varepsilon_{t}, \varepsilon_{t}^{\prime}\right)=\sum_{\varepsilon}$, the variance-covariance matrix for the structural shocks. In the above notations, we can find expressions in terms of long run multipliers of the response of inflation and real stock prices to these structural shocks. These are $\gamma_{s \pi}=\alpha_{s \pi}(1) / \alpha_{s s}(1)$ and $\gamma_{\pi s}=\alpha_{\pi s}(1) / \alpha_{\pi \pi}(1)$ where $\gamma_{s \pi}$ measures the long run response of real stock prices, $s_{t}$ to a permanent unit increase in inflation, $\pi_{t}$, while $\gamma_{\pi s}$ measures the long run response of $\pi_{t}$ to a permanent unit increase in $s_{t}$.

Endogeneity of $s_{t}$ and $\pi_{t}$ makes the system of equations (1) and (2) unidentified and therefore we cannot obtain consistent estimates of $\gamma_{s \pi}$, the long run real stock price response to a permanent inflation shock. We identify three identifying schemes that use a pair of restrictions. Expressions (1) and (2) place 1's on the diagonal of $\alpha_{0}$ but only three of the remaining parameters $\operatorname{var}\left(\varepsilon_{t}^{\pi}\right) \operatorname{var}\left(\varepsilon_{t}^{S}\right) \operatorname{cov}\left(\varepsilon_{t}^{\pi}, \varepsilon_{t}^{S}\right), \lambda_{\pi s}$ and $\lambda_{s \pi}$ are identifiable. The $\sum_{\varepsilon}$ is diagonal is the first restriction used each of the three identifying schemes. We also follow the standard practice in structural VAR modeling and assume that the structural shocks are contemporaneously uncorrelated, that is, $\operatorname{cov}\left(\varepsilon_{t}^{\pi}, \varepsilon_{t}^{S}\right)=0$. This assumption places no restriction on the contemporaneous correlation between $s$ and $\pi$, as long as $\lambda_{\pi s}$ and $\lambda_{s \pi}$ are allowed to be non-zero. By following Rapach (2002), we discuss the importance of the three identifying schemes in the interpretation of the results as follows:

a) The first identifying scheme assumes that $\sum_{\varepsilon}$ is diagonal and $\lambda_{\pi s}$ is known. The assumption restricts the contemporaneous response of $\pi$ to a permanent real stock price shock. Standard theory suggests that in the short run, inflation should respond negatively to a permanent real stock price shock implying that $\lambda_{\pi s}$ is negative in most cases. This is because a permanent real stock price chock can be perceived as a productivity shock that permanently increases real output and hence expected earnings.

b) In the second identification scheme, $\sum_{\varepsilon}$ is diagonal and $\lambda_{s \pi}$ is known, implying that we restrict the contemporaneous real stock price response to a permanent inflation shock. A permanent inflation shock, say, due to an accommodative monetary policy by the Reserve Bank, reduces the real interest rate, thereby increasing real output and real earnings in the short run ${ }^{4}$. Thus, in the short run $\lambda_{s \pi}$ is expected to be positive if a short run liquidity effect prevails.

c) The third identifying scheme assumes that $\sum_{\varepsilon}$ is diagonal and $\gamma_{\pi s}$ is known. This restricts the Reserve Bank's long run response to a permanent real stock price shock. If the Reserve Bank increases the target inflation rate in response to a productivity shock, then $\lambda_{\pi s}$ is expected to be positive; it is expected to be negative if the Bank's response to the shock is by lowering the target inflation rate.

With the above identifying assumptions, we have consistent estimates of the parameters of equations (1) and (2), from which we can generate $\gamma_{s \pi}$ estimates. The results

\footnotetext{
${ }^{4}$ based on the standard present value equity valuation model, falling interest rate and rising real earnings leads to an increase in real stock prices.
} 
are discussed in the next section. In order to check for robustness and plausibility of the estimates of the long run neutrality inferences made, we generate $\gamma_{s \pi}$ estimates for different values of $\lambda_{\pi s}, \lambda_{s \pi}$ and $\gamma_{\pi s}$.

\section{Empirical findings}

Panels A, B and C of Figure 1 present point estimates of $\gamma_{s \pi}$ based on the first identification scheme, second identification scheme and third identification scheme respectively. The dashed lines delineate $95 \%$ confidence bands.

\subsection{First identification scheme}

Panel A of Figure 1 depicts $\gamma_{s \pi}$ point estimate as decreasing for the assumed values of $\lambda_{\pi s} . \lambda_{\pi s}$ values that are approximately less than zero produce $\gamma_{s \pi}$ estimates that are significantly positive. For instance, for the value $\lambda_{\pi s}=-0.05$, we have a corresponding significant $\gamma_{s \pi}$ value of approximately 12 . This suggests that inflation decreases contemporaneously by 0.5 percentage points for each $10 \%$ increase in real stock prices, whereas the $\gamma_{s \pi}$ of 12 implies that long run real stock prices increases by 12 percentage for each percentage point increase in inflation resulting from a permanent inflation shock.

Since theory suggests that $\lambda_{\pi s}$ is likely to be negative, the range of $\lambda_{\pi s}$ values between -0.10 and 0.00 seem quantitatively plausible for South Africa. This implies that only $\lambda_{\pi s}$ values that are very close (or equal) to zero produce point estimates that are not significantly different from zero. These are the values that correspond to long run inflation neutrality with respect to real stock prices. The $\gamma_{s \pi}$ values that correspond to the range of positive values of $\lambda_{\pi s}$ are significantly negative. But, given that theory suggests $\lambda_{\pi s}$ to be negative, these $\gamma_{s \pi}$ estimates are unreasonable at least according to theory.
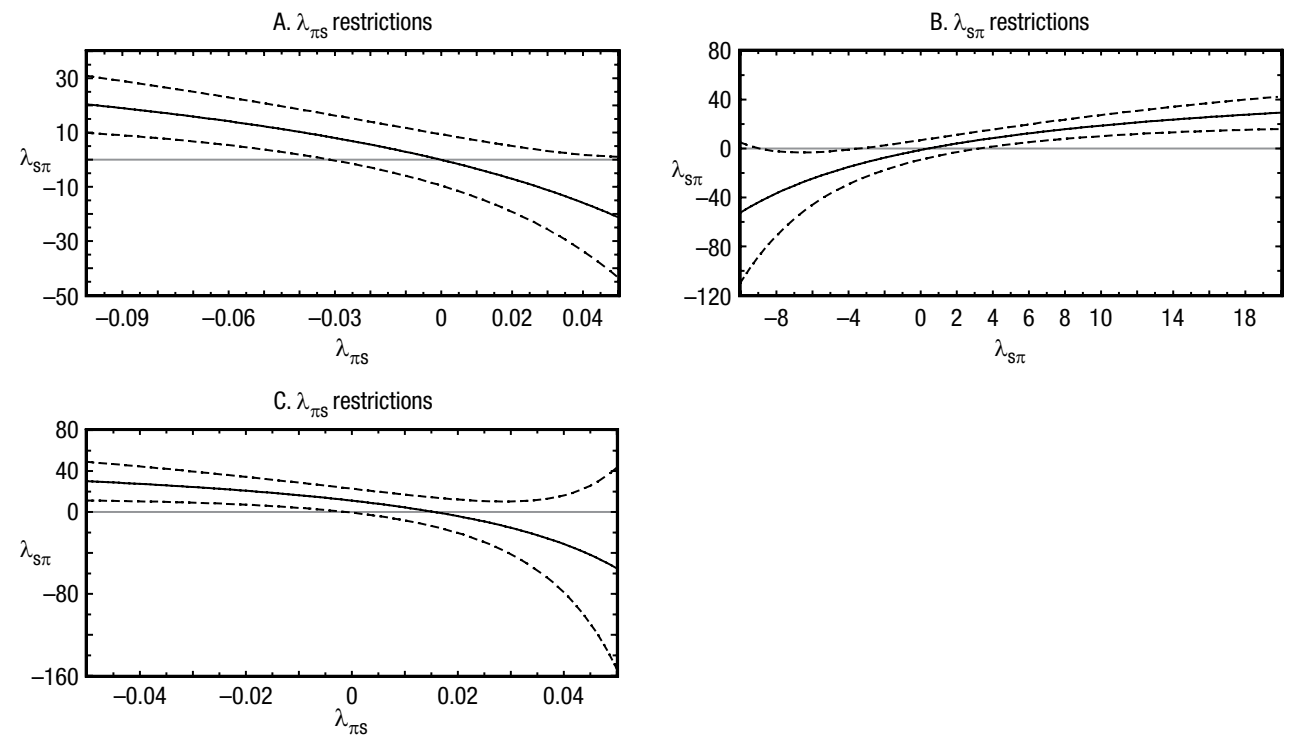

Fig. 1. $\gamma_{s \pi}$ estimates for different assumed $\lambda_{\pi s}, \lambda_{s \pi}$ and $\gamma_{\pi s}$ values 
In Figure 2 we present the impulse responses of inflation and real stock price for three different assumed $\lambda_{\pi s}$ identifying values $(-0.05,0,0.05)$. These values do not produce significant differences in inflation response to a permanent inflation shock or in real stock price response to a permanent real stock price shock. However there are notable differences in inflation response to a permanent real stock price shock and in real stock price response to a permanent inflation shock for these assumed values of $\lambda_{\pi s}$.

Earlier in Figure 1 it was noted that the value of $\lambda_{\pi s}=-0.05$ yields positive and significant $\gamma_{s \pi}$ point estimate. From the impulse responses (in Figure 2) it is observed that, for $\lambda_{\pi s}=-0.05$, a permanent inflation shock produces a short run increase in real stock prices, and a permanent real stock price shock produces a noticeable short run decrease in inflation.

For $\lambda_{\pi s}=0$ (which generates a $\gamma_{s \pi}$ estimate that is not significantly different from zero) the short run inflation response to a permanent real stock price shock is positive, whereas the short run real stock price response to a permanent inflation shock is negative. These results are theoretically implausible. When $\lambda_{\pi s}=0.05$ (positive $\lambda_{\pi s}$ values yield $\gamma_{s \pi}$ estimates that are significantly negative) it is observed that, the short run response of real stock prices to a permanent inflation shock is negative, whereas the short run response of inflation to a permanent real stock price shock is positive. These findings do not correspond to theoretical expectations. Overall, on the basis of the first identification scheme, it is observed that $\lambda_{\pi s}$ values that are associated with positive $\gamma_{s \pi}$ point estimates are theoretically plausible.
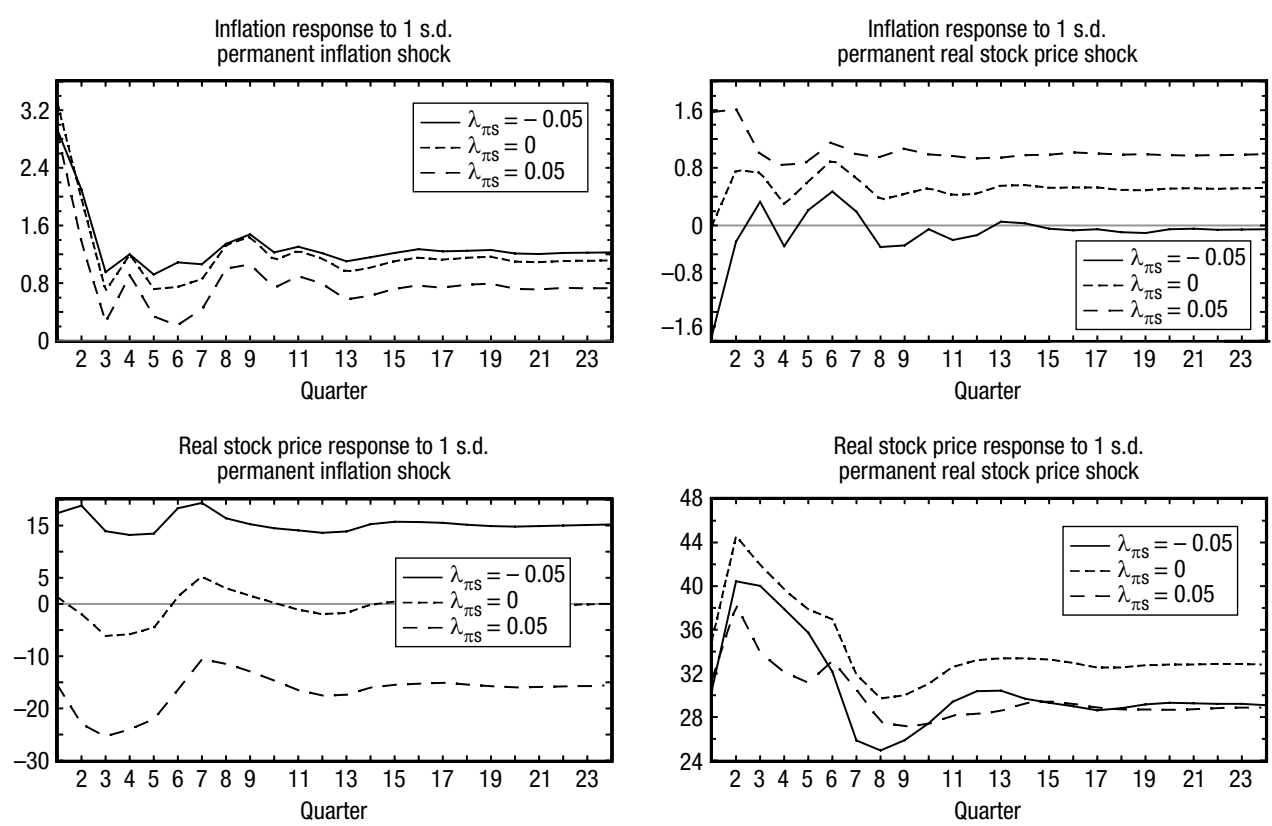

Fig. 2. Inflation and real stock price impulse responses for different assumed $\lambda_{\pi s}$ values 


\subsection{Second identification scheme}

Panel B of Figure 1 reports point estimates of $\gamma_{s \pi}$ based on the second identification scheme. We can observe that positive assumed $\lambda_{s \pi}$ values produce significantly positive $\gamma_{s \pi}$ point estimates, whereas negative assumed $\lambda_{s \pi}$ values yield significantly negative $\gamma_{s \pi}$ point estimates. Values of $\lambda_{s \pi}$ that are close to zero yield $\gamma_{s \pi}$ point estimates that are not significantly different from zero. A value of $\lambda_{s \pi}=8$ for instance, corresponds to a $\gamma_{s \pi}$ value of approximately 16. It suggests that real stock prices increase contemporaneously by 8 percent for each percentage point increase in inflation. The $\gamma_{s \pi}$ value of 16 implies that the long run real stock prices increase by 16 percent for each point increase in inflation resulting from a permanent inflation shock. It can therefore be concluded that, positive values of $\lambda_{s \pi}$ (which yield positive $\gamma_{s \pi}$ point estimates) are theoretically plausible and this is consistent with liquidity effect, where a permanent inflation shock lowers the real interest rate, and this increases both real output and real earnings in the short run. This in turn should increase real stock prices.

The corresponding impulse responses for three different assumed identifying values of $\lambda_{s \pi}(-6,1$ and 8$)$ are displayed in Figure 3, and they confirm the above results. It is observed that positive values of $\lambda_{s \pi}$ such as 1 and 8 for instance, yield significantly positive real stock price response to a permanent inflation shock, in line with theoretical expectations. The impulse response for $\lambda_{s \pi}=8$ far much exceeds those of $\lambda_{s \pi}=1$.
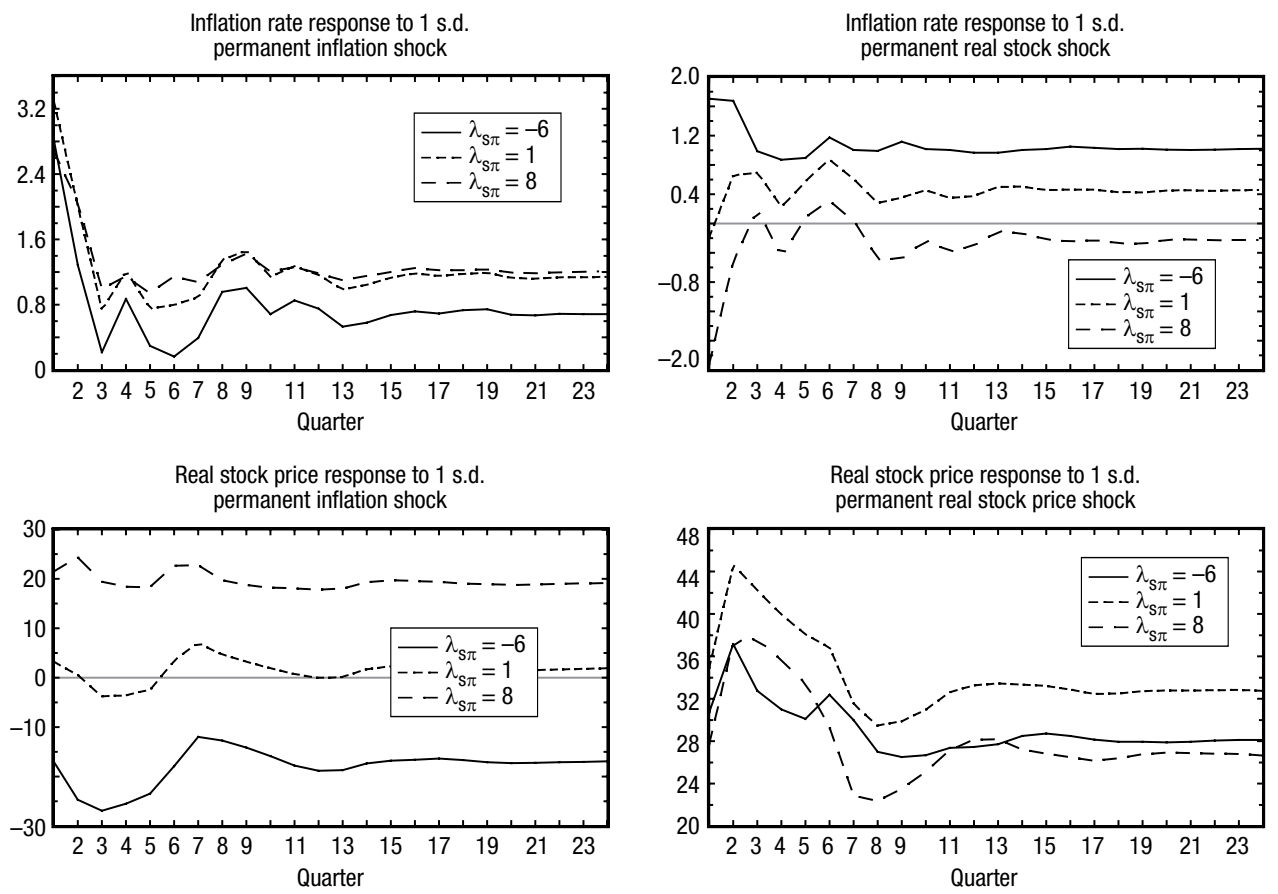

Fig. 3. Inflation and real stock price impulse responses for different assumed $\lambda_{s \pi}$ values 
It is however observed that, whereas the inflation rate response to a permanent real stock price shock is primarily positive for $\lambda_{s \pi}=1$, it is primarily negative for $\lambda_{s \pi}=8$, implying that there is a limit of positive assumed $\lambda_{s \pi}$ values for which inflation response to a permanent real stock price shock is positive.

Finally, whereas negative assumed $\lambda_{s \pi}$ values (such as $=\lambda_{s \pi}-6$ ) yield primarily negative real stock price responses to a permanent inflation shock, they yield primarily positive inflation responses to a permanent real stock price shock.

\subsection{Third identification scheme}

Panel C of Figure 1 reports $\gamma_{s \pi}$ point estimates for different assumed $\gamma_{\pi s}$ identifying values based on the third identification scheme (that $\sum_{\varepsilon}$ is diagonal and $\gamma_{\pi s}$ is known). It depicts $\gamma_{s \pi}$ point estimates to be decreasing for increasing $\gamma_{\pi s}$ values. $\gamma_{\pi s}$ values of approximately less than 0.015 produce significantly positive $\gamma_{s \pi}$ point estimates while those above it yield significantly negative $\gamma_{s \pi}$ point estimates.

As noted earlier, theory is inconclusive on the expected sign of $\gamma_{\pi s}$. From the impulse responses reported in Figure $4, \gamma_{\pi s}$ values above 0.015 are associated with a positive inflation response to a real stock price shock, reflecting higher target inflation rate by the Reserve Bank in response to a productivity shock. Rapach (2002) observes that an assumed value of $\gamma_{\pi s}$ equal to zero corresponds to the "monetarist" assumption that permanent changes in inflation arise mainly from exogenous changes in money growth. In that case $\gamma_{s \pi}$ is reasonably equal to zero, a result that has been found for most countries.
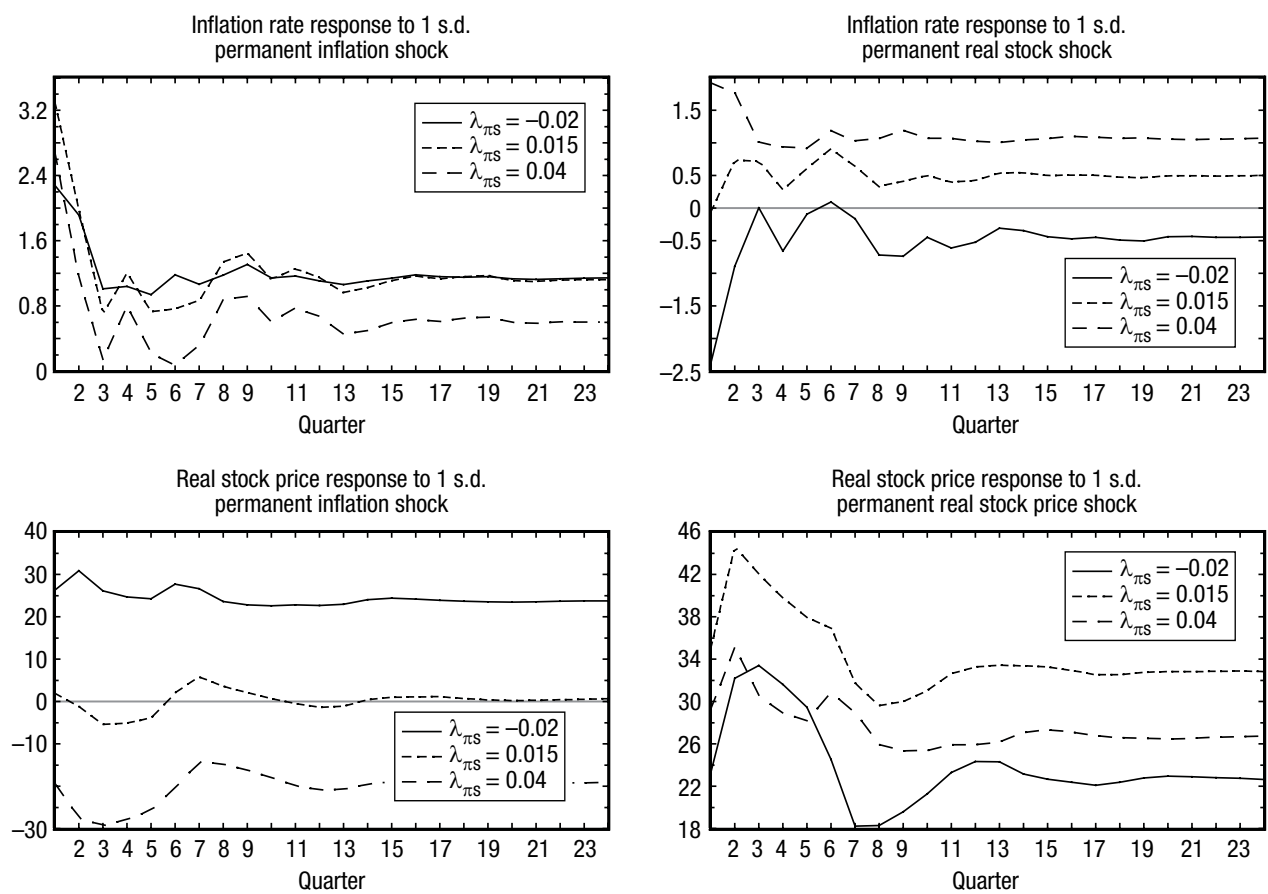

Fig. 4. Inflation and real stock price impulse responses for different assumed $\gamma_{\pi s}$ values 


\section{Conclusion}

The paper has examined the long run relationship between inflation and real stock prices in South Africa within the bivariate vector autoregressive (VAR) framework. Overall, we find considerable evidence in support of the view that, in the long run real stock prices are invariant to permanent changes in the rate of inflation. The impulse responses reveal a positive real stock price response to a permanent inflation shock in the long run, indicating that any deviations in short run real stock prices will be corrected towards the long run value. Therefore the long run estimates of the real stock price response to a permanent inflation shock that are zero or positive are theoretically plausible.

The impulse responses also provide support for a positive liquidity effect with respect to real stock prices, where a permanent inflation shock lowers the real interest rate. This then increases both real output and real earnings in the short run, which in turn raises real stock prices. Intuitively, these findings imply that investment in real stocks can provide a hedge against inflation in South Africa, at least in the long run. Our findings coincide with those from studies by Rapach (2002), Kim (2003) and Al-Khazali and Pyun (2004), Tvaronavičienė and Michailova (2006), Alagidede and Panagiotidis (2010) and Wei (2010). However we do not find considerable evidence in support of an inverse relationship between inflation and real stock prices as suggested by Modigliani and Cohn (1979), Feldstein (1980), Fama (1981), Devereux and Yetman (2002), Gallagher and Taylor (2002) and Anari and Kolari (2010).

\section{References}

Alagidede, P.; Panagiotidis, T. 2010. Can common stocks provide a hedge against inflation? Evidence from African countries, Review of Financial Economics 19: 91-100.

http://dx.doi.org/10.1016/j.rfe.2010.04.002

Al-Khazali, O. M.; Pyun, C. S. 2004. Stock prices and inflation: new evidence from the pacificbasin countries, Review of Quantitative Finance and Accounting 22: 123-140.

http://dx.doi.org/10.1023/B:REQU.0000015853.16564.e3

Anari, A.; Kolari, J. 2001. Stock prices and inflation, The Journal of Financial Research 24(4): 587-602.

Anari, A.; Kolari, J. 2010. The Power of Profit, Business and Economic Analyses, Forecasting and Stock Evaluation. New York: Springer-Verlag.

Brandt, M. W.; Wang, K. Q. 2003. Time-varying risk aversion and unexpected inflation, Journal of Monetary Economics 50: 1457-1498. http://dx.doi.org/10.1016/j.jmoneco.2003.08.001

Campbell, J. Y.; Vuolteenaho, T. 2004. Inflation Illusion and Stock Prices, NBER Working Paper (National Bureau of Economic Research) No. 10263.

Cohen, R. B.; Polk, C.; Vuolteenaho, T. 2005. Money Illusion in the Stock Market: the Modigliani-Cohn Hypothesis, NBER Working Paper Series (National Bureau of Economic Research) No. 11018.

Contrarian Investors' Journal. 2010. Can stocks hedge you from price inflation [cited 18 October 2010]? Available from Internet: http://cij.inspiriting.com/?tag=price-inflation

Crosby, M.; Otto, G. 2000. Inflation and capital stock, Journal of Money, Credit and Banking 32(2): 236-253. http://dx.doi.org/10.2307/2601241 
Devereux, M. B.; Yetman, J. 2002. Menu costs and the long-run output-inflation trade-off, Economic Letters 76: 95-100. http://dx.doi.org/10.1016/S0165-1765(02)00022-8

Dickey, D. A.; Fuller, W. A. 1979. Distribution of the estimators for autoregressive time series with a unit root, Journal of the American Statistical Association 76(366): 427-431.

Elliot, G.; Rothenberg, T. J.; Stock, J. H. 1996. Efficient tests for an autoregressive unit root, Econometrica 64(4): 813-836. http://dx.doi.org/10.2307/2171846

Engel, R.; Granger, W. 1987. Co-integration and error correction representation, estimation and testing, Econometrica 55: 251-276. http://dx.doi.org/10.2307/1913236

Fama, E. 1981. Stock returns, real activity, inflation and money, American Economic Review 71: $545-565$.

Feldstein, M. 1980. Inflation and the stock market, American Economic Review 70(5): 839-847.

Fisher, I. 1930. The Theory of Interest. New York: Macmillan.

Fisher, M. E.; Seater, J. J. 1993. Long-run neutrality and superneutrality in an ARIMA framework, American Economic Review 83(3): 402-415.

Gallagher, L. A.; Taylor, M. P. 2002. The stock return-inflation puzzle revisited, Economic Letters 75: 147-156. http://dx.doi.org/10.1016/S0165-1765(01)00613-9

Geske, R.; Roll, R. 1983. The fiscal and monetary linkages between stock returns and inflation, Journal of Finance 38(1): 49-65.

Hong, G.; Lee, B.-S. 2011. Is mispricing in asset prices due to inflation illusion? Department of Finance, College of Business, Florida State University, Mimeo.

Kim, J. R. 2003. The stock return-inflation puzzle and the asymmetric causality in stock returns, inflation and real activity, Economic Letters 80: 155-160.

http://dx.doi.org/10.1016/S0165-1765(03)00059-4

King, R. G.; Watson, M. W. 1997. Testing long-run neutrality, Federal Reserve Bank of Richmond Economic Quarterly 83(3): 69-101.

Koustas, Z.; Serletis, A. 1999. On the Fisher effect, Journal of Monetary Economics 44(1): 105-130. http://dx.doi.org/10.1016/S0304-3932(99)00017-3

Kwiatkowski, D.; Phillips, P. C.; Schmidt, P.; Shin, Y. 1992. Testing the null hypothesis of stationaity against the alternative of a unit root, Journal of Econometrics 54: 159-178. http://dx.doi.org/10.1016/0304-4076(92)90104-Y

Marshall, D. A. 1992. Inflation and asset returns in a monetary economy, Journal of Finance 47(4): 1315-1342.

Modigliani, F.; Cohn, R. A. 1979. Inflation, rational valuation and the market, Financial Analysis Journal 35(2): 24-44. http://dx.doi.org/10.2469/faj.v35.n2.24

$\mathrm{Ng}, \mathrm{S}$;; Perron, P. 2001. Lag-length selection and the construction of unit root tests with good size and power, Econometrica 69: 1519-1554. http://dx.doi.org/10.1111/1468-0262.00256

Quayes, S.; Jamal, A. 2008. Does inflation affect stock prices?, Applied Economics Letters 15: 767-769. http://dx.doi.org/10.1080/13504850600770871

Rapach, D. E. 2002. The long-run relationship between inflation and real stock prices, Journal of Macroeconomics 24: 331-351. http://dx.doi.org/10.1016/S0164-0704(02)00041-1

Ritter, J. R.; Warr, R. S. 2002. The decline of inflation and the bull mareket of 1982-1999, Journal of Financial and Quantitative Analysis 37: 29-61. http://dx.doi.org/10.2307/3594994

Shin, Y. 1994. A residual-based test of the null of cointegration against the alternative of no integration, Econometric Theory 10(1): 91-115. http://dx.doi.org/10.1017/S0266466600008240

Tobin, J. 1965. Money and economic growth, Econometric 32: 671-684.

http://dx.doi.org/10.2307/1910352 
Tvaronavičienė, T.; Michailova, J. 2006. Factors affecting securities prices: theoretical versus practical approach, Journal of Business Economics and Management 7(4): 213-222.

Wei, C. 2010. Inflation and stock prices: no illusion, Journal of Money, Credit and Banking 42(2): 325-345. http://dx.doi.org/10.1111/j.1538-4616.2009.00289.x

Riona ARJOON. I am an economist in the Economic Analysis and Research division in Statistics South Africa. I completed my BSc (Honours) in Statistics at the University of Kwa-Zulu Natal and I am currently in the final year of my MPhil in Economics at the University of Pretoria. My academic interests are mainly Macroeconomic Policy and Time Series Econometrics.

Mariëtte BOTES. At present I am completing my MCom degree in Economics at the University of Pretoria. This past semester I was employed as a junior lecturer for undergraduate Macroeconomics at this university. As of August 2011 I will be studying towards an MSc in Economics at Tilburg University in the Netherlands. My academic interests are mainly International and Financial economics with my MCom dissertation focussing on International Financial Contagion during the 2008 financial crisis.

Laban K. CHESANG. I am currently pursuing Ph.D. in the department of Economics, University of Pretoria. Prior to enrolling for Ph.D., I have been working as a Lecturer in the School of Business and Economics at Daystar University in Kenya from January 2006 to December 2009. I obtained my MA degree from the University of Botswana in October 2005 and the BA (Honours) degree from Egerton University, Kenya. My academic interests are mainly monetary economics, economic growth and time series econometrics.

Rangan GUPTA. I am currently a Professor at the Department of Economics, University of Pretoria. After having completed my Ph.D. in May 2005 from the Department of Economics, University of Connecticut, I joined the Department of Economics, University of Pretoria, as a Senior Lecturer in August 2005 and got promoted to an Associate Professor in July 2007. I secured my BSc (Honours) degree from the R.K.M.R. College, Narendrapur, and the MSc degree from the University of Calcutta. My academic interests are mainly Monetary Theory and Policy, Business Cycles, and Time Series Econometrics. I have published in wide number of internationally accredited journals. 